\title{
Kindergarten Teachers' Perspective on Early Intervention in Autism Spectrum Disorders
}

\author{
Ana Paula Caeiro* and Vítor Franco
}

CIEP- Center for Research in Education and Psychology, University of Evora, Portugal

\begin{abstract}
In Portugal, children with developmental disorders are supported by the National Early Childhood Intervention System (NECIS). This network aims to promote child development from a family-centered perspective, based on community support and carried out in everyday natural contexts by a transdisciplinary team.

This study aims to verify how the NECIS responds to the needs identified by educators who receive children with Autism Spectrum Disorder (ASD) in pre-school. This is a qualitative, multiple case study using the content analysis of 6 semistructured interviews. The results show that these educators feel ill-prepared to work with children with ASD. They expect NECIS professionals will perform more targeted and rehabilitative work with the child and point out the limited time that they have to spend with children as one of the main constraints.
\end{abstract}

Keywords: Early Intervention, Autism Spectrum Disorder, Kindergarten Teachers, Preschool, Collaborative Consulting.

\section{INTRODUCTION}

Early Childhood Intervention $(\mathrm{ECl})$ is characterized by a set of interventions aimed at children under 6 years old, with developmental disorders or at risk of developing them [1]. As a multidimensional, contextualized and individualized practice centered on the child and the family, it aims to ensure good practices that facilitate and promote the child's fullest development and promote their fullest utmost inclusion in various contexts [2].

The theoretical contributions of three major areas of knowledge, neurosciences [3,4], research on early development $[5,6]$, and the contextual and ecological perspectives of development $[7,8]$, combine to enables a more comprehensive, systemic, and holistic approach, increasing the possibilities of intervention and, therefore, the challenges that arise. The evolution from a perspective of stimulation to this family-centered perspective, involving the child and family's natural contexts and routines, with co-responsibility shared and training provided to the main caregivers [9], is based on three basic principles present in the Portuguese legislative framework [10]. The principle of globality, which views the child as a whole, the principle of contextuality, which refers to a child's view within its multiple contexts, and the principle of opportunity, proposing interventions should occur as soon as possible [2].

*Address correspondence to this author at the Center for Research in Education and Psychology, University of Evora, Portugal; Tel: +351266 768 050; E-mail: anapaulacaeiro@hotmail.com, vfranco@uevora.pt
The primary objective of the $\mathrm{ECl}$ is to promote the competence and trust of parents and the child's key care providers, creating learning opportunities that promote development, strengthening, and optimizing positive functioning patterns and family interactions $[11,12]$. ECl programs emphasize that it is in meaningful experiences, relationships, and day-to-day opportunities that early learning takes place. The focus is on family and community resources, working in environments and developmentally appropriate contexts [13].

The $\mathrm{ECl}$ network in Portugal was implemented through the coordinated action of the Ministries of Labour and Social Solidarity (MLSS), Health (MH), and Education (ME), and is defined as a community-based service, guaranteed by local intervention teams (LIT). These multidisciplinary teams are the functional base of the entire system, responsible for providing close support to children and families, and made up of professionals from various areas (kindergarten teachers, special education teachers, social service technicians, psychologists, therapists, nurses, among others). Among the key functions assigned to LITs, one is the articulation with the teachers of the daycare centers and kindergartens in which the children are included [10], whether these pre-school establishments are from a public, private, or solidarity network (private social security institutions - PSSI).

This close collaboration with the educational teams translates into the provision of collaborative consultancy services, essential to achieving the child's ultimate goal of learning and development. 
Collaborative consultancy in this area corresponds to a practice of triadic relationships within a given context. This involves a consultant (i.e., ECI professional) and a consultee (i.e., kindergarten teacher), in which the latter acquires skills that assist him in actively participating in the process(es) of promoting child development [14,15]. The educator contributes with his/her knowledge of the child, its peers, and the functioning of his classroom. The ECl professional shares the specific knowledge of the training areas of the elements of his transdisciplinary team, along with a different viewpoint on the class, from an outsider's perspective, encouraging and supporting the educator to implement the defined strategies [15,16]. Collaborative consultancy, unlike specialized consultancy, involves deciding hand in hand with the educator on the problem, the possible solutions, and whether these are working. This interaction, between ECl professional and educator, occurs during visits to the educational setting, strengthening the educator's confidence and competence, who is responsible for the results, which in turn leads to the improvement of learning and development opportunities offered to the child [17].

These collaborative consultancy processes, based on equitable and reciprocal relationships between professionals and with families, allow the design of interventions that legitimize the various experiences of individual children in different contexts, valuing caregivers' knowledge and skills.

Bearing in mind that access to education is a recognized right for all, based on equal opportunities, attendance of a quality educational context implies that educators organize the contexts in order to accommodate all children, regardless of their physical, intellectual, emotional, linguistic, or social conditions, helping them to achieve the objectives proposed for their level of development [18].

In Portugal, $21 \%$ of groups in pre-school education include children with special needs, which represents a challenge for early childhood education professionals as essential elements in the $\mathrm{ECl}$ process.

Receive all children in pre-school, ensuring their participation and involvement in activities and routines with significant adults and their peers, implies, first, that educators know the children's behaviors and difficulties, and that the school has adequate human and material resources to accompany and support the child in developing their abilities $[17,19,20]$.
Among the developmental and behavioral disorders that can be found in pre-school rooms, we have Autism Spectrum Disorder (ASD), which, according to multiple studies, has been on the rise in recent decades [2125]. However, it is not yet understood whether this increase effectively reflects an increase in the number of cases or is due to the expansion of diagnostic criteria. Despite this, it is now possible to identify signs that lead to an increasingly earlier diagnosis, enabling a timelier intervention $[23,26]$.

ASD is a neurodevelopmental disorder characterized by difficulties in terms of communication and social relationships, marked by repetitive and stereotyped activities and behaviors, affecting the way the child observes, perceives, and understands the world around him/her/them. Such changes become evident during early childhood, and these children often demonstrate little or no interest in social interactions and maybe being a regression in some areas of development and constraints in language skills [27].

Educators who receive a child with ASD face the challenge of adapting and organizing educational environments and planning their practice in a flexible manner so that these children can experience life and learning situations and get involved with peers and contexts.

These circumstances imply that educators assume a more comprehensive attitude and an articulated, contextualized, personalized, and often more systematic, and even more carefully planned practice, adapting classroom activities and routines to the child's needs for involvement, participation, and social interactions, taking advantage of these natural opportunities for development and learning $[16,28]$.

Most studies out so far in Portugal focus on the perceptions of professionals and families regarding $\mathrm{ECl}$, with data collected through questionnaires or interviews [29-35]. Studies carried out based on the observation of practices are scarce $[36,37]$. In general, the results point to a gap between the recommended practices $[1,9,16]$, based on a family-centered approach, and the standard practices of professionals [13].

The present study hinges on the research question, "how do LITs respond to the needs identified by early childhood educators who receive children with ASD in their pre-school rooms?", developed through the following specific objectives: 
a) Identify what kindergarten teachers know and think about ASD;

b) Identify how the educators organized themselves to receive the child with ASD in the kindergarten and what difficulties they encounter in their daily work, taking into account the perceived needs;

c) Identify how educators perceive the $\mathrm{ECl}$ service with children with ASD and how it responds to the needs they recognize.

Considering that a set of essential conditions is necessary to develop a quality $\mathrm{ECl}$, this research aims to identify better and understand the difficulties educators encounter in their work in children with ASD. Also, the way that $\mathrm{ECl}$ teams help them find effective strategies to promote the development and participation of these children in pre-school rooms.

\section{METHOD}

The present study was designed based on a qualitative approach [38], as this seems to serve its goals best. Bearing in mind that we are speaking about educational phenomena, a field of research where moments are unique and unrepeatable, perceived and interpreted differently by its stakeholders, it seemed essential to choose a methodology that takes into account not only the defined object of study and the objectives set but also this singularity. We intend to listen to educators and collect their perceptions in a broad fashion about the $\mathrm{ECl}$ teams' functioning with children with ASD and their articulation with educational environments.

A multiple case study was implemented since the intent was to emphasize the particular, descriptive, heuristic, inductive and holistic character of the specific situation, taking into account the contextual conditions in which it occurs.
The semi-structured interview was the data collection technique used, built from a previously prepared interview guide.

Six kindergarten teachers were interviewed, who work in educational establishments in the private and social solidarity network and who receive children diagnosed with moderate-severe ASD in their classrooms. The selection of these participants was made by convenience, with all participants working in the district of Setúbal (Portugal).

Data collection was carried out after the authorization request and free and informed consent, ensuring the respondents' confidentiality, privacy, and anonymity, respecting the ethical principles of scientific research [38].

The data were then subjected to categorical content analysis via a line-by-line interpretive analysis, comparing the theoretical reference framework with the empirical material collected. A system of categories was constructed in a deductive and inductive way, with the relevant categories and subcategories of analysis resulted from both the review of the literature and the reading of the data. Analysis was carried out in three phases: the pre-analysis; the exploration of the material and the treatment of the results, with the respective inferences; and the interpretation of the results [39].

To ensure credibility, peer review was employed, submitting the results to two professionals who, not belonging to the investigation, were knowledgeable in the subject matter and the research process, enabling them to analyze and check the research data.

\section{RESULTS}

The results were grouped into three sets, taking into account the research objectives: a) Educators' conceptions about children with ASD; b) Educational

Table 1: Description of Participants

\begin{tabular}{|c|c|c|c|c|}
\hline Participant & Age & Training Level & Years of service & Type of Institution \\
\hline \hline Educator 1 & 45 & Bachelor's Degree + Training Supplement & 21 & PSSI \\
\hline Educator 2 & 39 & Degree + Post-Graduation in Special Education & 16 & Private \\
\hline Educator 3 & 37 & Degree + Post-Graduation in Early Intervention & 14 & PSSI \\
\hline Educator 4 & 36 & Graduation & 10 & Private \\
\hline Educator 5 & 34 & Graduation & 23 & Private \\
\hline Educator 6 & 48 & Bachelor's Degree + Training Supplement & Private \\
\hline
\end{tabular}


Table 2: Summary of Categories and Subcategories

\begin{tabular}{|c|c|c|}
\hline & Categories & Subcategories \\
\hline \multirow[t]{2}{*}{$\begin{array}{l}\text { Educator's Conceptions about } \\
\text { Children with ASD }\end{array}$} & Knowledge & $\begin{array}{l}\text { Knowledge from Training } \\
\text { Resource Mobilization }\end{array}$ \\
\hline & Representations & $\begin{array}{c}\text { Initial Representations about ASD } \\
\text { Representations arising from experience }\end{array}$ \\
\hline \multirow{2}{*}{$\begin{array}{l}\text { Educational intervention with } \\
\text { children with ASD }\end{array}$} & Educational Intentionality & Objectives of Pedagogical Practice \\
\hline & $\begin{array}{l}\text { Organization of the Educational } \\
\text { Environment }\end{array}$ & $\begin{array}{l}\text { Educational Room Environment } \\
\text { Interactions and Relationship with Children with ASD }\end{array}$ \\
\hline \multirow[t]{2}{*}{ Educator's Views on ECI Practice } & $\begin{array}{c}\text { Interaction of the ECI Professional in the } \\
\text { Educational Context }\end{array}$ & $\begin{array}{l}\text { Positive Dynamics } \\
\text { Negative Dynamics }\end{array}$ \\
\hline & Importance of the ECI Service & $\begin{array}{l}\text { ECI Weaknesses or Constraints } \\
\text { Recommendations }\end{array}$ \\
\hline
\end{tabular}

intervention with children with ASD; and c) Educators' perspective on the practice of $\mathrm{ECl}$.

\section{Educators' Conceptions about Children with ASD}

We found two categories: knowledge and representations.

a) The Knowledge category concerns the origin of educators' knowledge, with two subcategories being distinguished: knowledge acquired from training and resource mobilization (or knowledge derived from the active search for resources).

As for the Knowledge from Training, the interviewees considered that the theme of Special Educational Needs and ASD were little or not addressed during their initial training.

"During the course, we got some vague highlights about what it is and what pathologies there were. But I think it ended up not being very focused." (E3)

"It was not a very talked-about topic. It is a big lapse that I think exists" (E5)

On the other hand, in the Resource Mobilization subcategory, educators maintained a proactive attitude of seeking more information, mainly research, sharing with other colleagues, and specialized continued training.

"I started to investigate a little" (E1)

"I looked to colleagues, looked at colleagues' experiences, to see how they handled it' (E5) b) The Representations category refers to the beliefs and ideas that educators held about children with ASD, and it is possible to distinguish the initial representations and those resulting from the experience.

The Initial Representations about ASD refers to the fact that when they receive a child with ASD, educators feel insecure due to the lack of specific training or the lack of knowledge on how to intervene. They also consider that there is no specific support and that interventions with these children will be more difficult than in other problems.

"Very complicated! One thing is a child who has a language delay or who has behavioral difficulties. Another thing entirely is a child with autism. It's completely different." (E1)

There are, however, other Representations that stem from the experience: everyone considers that, despite being a demanding and challenging job requiring dedication and commitment, theirs was a positive and rewarding experience, bringing a greater understanding of the problem/issue.

"It was, for me, a year of profound professional growth that this child brought me! And it made me see things differently. What I thought was the degree of understanding of this child did not correspond a bit to the idea that I had initially." (E1) 


\section{Educational Intervention with Children with ASD}

Two categories were found: one related to educational intentionality and another to the organization of the educational environment.

a) The Educational Intentionality category is related to the educator's action and his practice's purpose. It was only possible to define one subcategory herein, related to the Objectives of Pedagogical Practice. The answers given indicate that these professionals do not have a defined purpose for action with these children, with little differentiation from what they generally practice.

"I always tried to get $X$ to do what other boys did" (E6)

b) The Organization of the Educational Environment has to do with the organization of the classroom, as a support to the educator's intentionality, with all the interactions and relationships that such contexts provide.

As for the Educational Room Environment, the responses highlighted the difficulty in managing the group within which the child with ASD is integrated and the need for more human resources (teachers or other support staff).

"So, what now, do I have to have you here the same time as the others? Do I let him go? Are you going to do what he wants, or do I have to manage things a little there?" (E5)

"And of course, being attentive to the group and being with $X$. who was crying, I ended up not being there for him, nor for the group, not for myself, not for anyone. That is why a third person in the room would be ideal." (E6)

Regarding the Interactions and Relationship with the Child with ASD, the educators identified difficulties in daily work with the child and the perception that their needs are very different from those found in other conditions, highlighting the difficulties in behavior management. They also point out the need for an individualized intervention for children with this disorder.

"Managing her behavior was very difficult. There were very desperate moments when she decompensated with a huge tantrum, kind of biting herself and biting us." (E3)

"It is completely different from any other child with SN (Special Needs). This child needs a person, needed a person right from the start, just for him. There is a moment when you still need it' (E1)

\section{Educators' Views on ECI Practice}

Regarding how educators perceive the intervention of the LIT that are part of the NECIS, we have grouped responses into two categories: the interaction of the IPI professional in the educational context and the perceived importance of the $\mathrm{ECl}$ service in general.

a) The category ECI Professional Interaction in the Educational Context refers to the way educators perceive the work the LIT carries out, highlighting the technical qualities and relational characteristics of the professionals as the basis for creating positive or negative dynamics in the Kindergarten context.

A set of Positive Dynamics related to the professionals' technical and relational aspects was identified/noted. Respondents highlighted the specific knowledge regarding $\mathrm{ASD}$, the theoretical-practical orientations imparted, and also their availability and respect for the educator's work.

"Because we planned things together, we set goals together, and we made small goals (...) We set small goals, and we tried to work both over a period of time to see if we could achieve it, then we evaluated... So, it was very much a shared chore here." (E3)

"Anyone I have spoken to about El has always been very available. They gave us a great help in terms of tips, what can we do and what can we not do, or what are the best ways to do it." (E4)

Respondents also mentioned some Negative Dynamics, a set of constraints of the $\mathrm{ECl}$ professional that makes it difficult to articulate in the educational context. Some refer to the lack of specific technical competence in the ASD area, others to difficulties in relational competencies, or even constraints in terms of service management and organization. 
"What I noticed through observation was extremely negative, because she didn't get anything from the child, there was... On the contrary, she ended up leaving with him in a small crisis. The crisis was left to me, who then had to calm him down." (E1)

"And we then came to a certain point that, for me, I ended up facing a really nosy attitude in my work. And I always think, complimenting me is one thing, setting me aside and going directly to the mother, contradicting what I said, is another. For me, that trust was completely broken. And that was a trust that was broken, and that never came back." (E1)

b) The Importance of ECI Service category reflects the relevance and value attributed by educators to work carried out by LITs in the field of ASD.

A set of Weaknesses or Constraints that work as a barrier to ELI intervention is identified. It includes the short time available for intervention with the child, the perception that the IPI professionals have a higher number of children than desired, and the teams' nonpermanence.

"... support educators have that time counted, and I don't know how many schools they have to support (...) to respond to requests from family, educators, children." (E1)

"I also put myself a lot in their skin, it's a bit boring going from school to school, sometimes I even feel like working with that child for a while and I can't. Time is up. Time shouldn't end!' (E2)

"... If a new technician comes every year, every year he tells the story. It is overwhelming to tell the story; I don't know how many times." (E3)

Educators also make some Recommendations that, from their point of view, could improve the $\mathrm{ECl}$ : the increase in intervention time and better management of time spent with the child and the educator, continuity of the case manager, increase in the number of professionals, and more differentiated and therapeutic support for the child, according to their particular needs.
"Time is the most fundamental characteristic so that they can spend more time with children" (E6)

"... If there is a continuity... we have already planned out for the following year what we had as objectives, and we all already knew (...) It was easier to adjust the work later because we no longer had to start over and make the adaptation and recognize the girl's characteristics because we all already knew, so there was a continuity (...) I think it would be beneficial for it always to be the same professional." (E3)

"I think that if it were part of the team ... There was a team with an educator, with a psychologist and a therapist, and that team worked together with this child, maybe it was much easier" (E5)

\section{DISCUSSION OF RESULTS}

All kindergarten teachers report limitations regarding the quality of the responses offered by $\mathrm{ECl}$ in the educational contexts where children with ASD are inserted. When evaluating the possibility of integrating children with ASD in their classrooms, they consider their training inadequate, pointing out the lack of material and human resources to meet and satisfy the needs of these children. This results in a pessimistic attitude regarding the work with these children. Research carried out by Pinto and Morgado [40] also shows that teachers consider their training insufficient and that they lack resources and support in their classrooms. Serrano and Afonso [41] stress the importance of pre-school education professionals benefitting from raining to work in an inclusive environment. Verifying teachers with more experience and knowledge regarding inclusion have more positive and more confident attitudes working with children with disabilities and SEN.

Similarly, Hammond and Ingalls [42] say that teachers with a lack of training feel uncomfortable, anxious, poorly prepared, and unsafe in their practice. Their social representations influence their practice with these children. Camargo and Bosa [43] also show that preconceived ideas about ASD influence the educator's expectations, interfering in promoting and enhancing the development of the child's skills. Studies by Connor and Ferri [19] indicate that it is essential that 
the school have quality human and material resources in order to provide the child with opportunities for participation and involvement.

Regarding the educational organization, we see a concern among educators to integrate children with ASD in their classrooms, despite mentioning that daily work is challenging, pointing out difficulties in planning and managing the group, requesting greater support from technicians, and expanding the classroom team. Correia [18] also writes on the challenge schools face of finding ways to respond effectively and distinctly o the needs of an increasingly heterogeneous school population. In the case of children with ASD, the challenge can become even greater, given that the manifestations of their behavior are one of the aspects that assume greater relevance in the social sphere.

With regard to the relationship between educators and the child with ASD, behavioral issues and communication difficulties emerge as the main obstacles. Behavioral problems seem to be reflected in the child's difficulties, needs, desires, and inflexibility in their daily routines and activities. Kristen et al. [44] indicate that the more the educator perceives the relationship with the child with ASD as positive, the more likely they are to reduce behavior problems, which is in line with our data.

Educators think that, in addition to interventions in context, these children need a specialized therapeutic intervention towards the acquisition and development of important skills and for the reduction of their behavioral symptoms, namely in the area of communication, sensory integration, and occupational therapy, which would fall under the purview of $\mathrm{ECl}$. Authors such as Johnson and Myers [22] argue that the intervention in ASD must be essentially educational, but that, in tandem with $\mathrm{ECl}$ intervention, direct behavioral and therapeutic strategies are essential to respond to these children's needs. McWilliam [17], Bowker et al. [45] and Dunst [46], however, point in the opposite direction, arguing that interventions based on a traditional intervention practice are ineffective with children so young, not only because of the difficulty of generalizing learning but also because in an isolated clinical context, it is possible to assess how the child effectively behaves in their daily contexts.

The educators' responses seem to point to a problem of comprehension of the $\mathrm{ECl}$ intervention model. This effect would prove important for LIT professionals, namely to explain the fundamentals and the way ECl works, namely what their role is in supporting the child's significant caregivers. This would clarify expectations and the intervention's objectives, reinforcing that professionals work as support and the intervention happens between their visits, since children at an early age develop and learn better through daily experiences in their contexts and with significant people [16,47-50].

This distance between the best practices in $\mathrm{ECl}$ and the recognition of its effectiveness in the context of early childhood education may contribute to understanding why educators consider that the collaborative consultancy work offered by $\mathrm{ECI}$ services is not sufficient to respond to the needs they recognized. This explains references that the frequency and intensity of interventions are not adequate to the children's needs.

Another weakness educators identified concerns the specific training that $\mathrm{ECl}$ professionals must have to intervene with children with ASD, given the particular set of difficulties these present, namely in terms of social communication and behavior, and the competing understandings of ASD and its implications for development and learning, the disorder's different manifestations, and the possible reasons (and triggers) for these children's behaviors. Along with theoretical and practical knowledge, interpersonal characteristics are noted as important, particularly the quality of professional interaction - a data point corroborated by the research by Boavida et al. [16] and Dunst [13].

Still, on the topics of teams, professionals' stability and permanence also seem to be considered a relevant condition for a relationship of trust between LIT professionals, families, and educators and for requisite for quality intervention.

\section{CONCLUSIONS}

The intervention of LIT professionals in educational contexts involves a collaborative perspective of adapting the classroom routines and activities to the child's needs with ASD so that the maximum gains in terms of natural opportunities for development and learning can be obtained. Local legislation regarding the inclusion of children with developmental disorders in educational settings follows international guidelines, which suggest that interventions should start as early as possible, include the child and family's active involvement, and the planning of meaningful activities. The child's developmental level must always be kept in 
mind, and their participation and involvement in all dayto-day activities included. It should also contemplate the bolstering and training of the main care providers.

The results obtained in the present research call attention to some potential flaws in current intervention with children with ASD by both the kindergarten teachers who receive them in their classrooms and in their collaboration with the $\mathrm{ECl}$ professionals who intervene in these contexts.

Regarding educators' conceptions about ASD, gaps are evident in terms of initial training, which condition their intervention with these children: when receiving a child with ASD, educators have limited capacity for pedagogical differentiation and face difficulties in planning an educational intervention with the child and difficulties in managing the group. This is justified by the scarcity of material and human resources in the room and the complexity of the child's characteristics resulting from ASD.

Regarding the $\mathrm{ECl}$ service, although the educators do not discard the work done by the LITs, they do identify a set of constraints on their action and make some practical recommendation to improve quality, such as: reducing the number of children; increasing the duration of the intervention; better organization and stabilization of the professionals within teams; and the need for adequate training of these professionals to intervene with children with this specific problem.

As this study is exploratory, and as a qualitative case study, it is limited by the number of educators who took part, so the results obtained, although valid for the universe studied, cannot be clearly extrapolated to the national level. Future research should seek to deepen, in a differentiated manner, the emergent aspects herein. Another limitation encountered and to be addressed in the future is related to the possible overlap between the categories and subcategories that may be equally further differentiated in future studies.

The results obtained indicate, in the light of the current $\mathrm{ECl}$ paradigm based on a collaborative consultancy model, that the expectations of early childhood educators seem to grant more value to the processes of direct intervention and rehabilitative work, identifying these as fundamental for the development and learning of children with ASD. It also seems to be unclear to them that the role of the $\mathrm{ECl}$ professional in educational contexts is to work with caregivers in the search for effective strategies to achieve the defined objectives and that the educator is responsible for implementing these strategies in daily routines, in the context of a dynamic, living relationship with the child.

\section{ACKNOWLEDGEMENTS}

This article was financed by national funds from FCT - Foundation for Science and Technology, I.P., within the scope of the project UIDB/04312/2020.

\section{REFERENCES}

[1] Correia LM, Serrano AM, organizers. Early family-centered intervention: an ecological perspective of service. Porto: Porto Publishing Company; 2000. p. 11-32.

[2] Franco V. Introduction to early intervention in child development: with the family, in the community, as a team. Évora: Aloendro' Editions; 2015.

[3] Johnston MV, Nishimura A, Harum K, Pekar J, Blue ME. Sculping the developing brain. Adv. Pediatric. 2001; 48: 1-38.

[4] Nelson, C. A. The Neurobiological Bases of Early Intervention. In: J. P. Shonkoff, and S. J. Meisels (Eds.) Handbook of Early Childhood Intervention (2nd Ed.). Cambridge, MA: Cambridge University Press 2000; pp. 20422.

https://doi.org/10.1017/CBO9780511529320.012

[5] National Institute of Child Health and Human Development Early Child Care Research Network. Child care effect sizes for the NICHD Study of Early Care and Youth Development. American Psychologist. 2006; 61: 99-116. https://doi.org/10.1037/0003-066X.61.2.99

[6] Shonkoff JP, Phillips DA, From neurons to neighborhoods: The science of early childhood development. Washington, DC: National Academy Press 2000.

[7] Bronfenbrenner U. Ecological system theory. Annals of Child Development. 1989; 6: 187-249.

[8] Sameroff AJ, Fiese BH. Transactional regulation: The developmental ecology of early intervention. In: Meisels SJ, Shonkoff JP, Handbook of Early Childhood Intervention. 2nd Ed. Cambridge: Cambridge University Press 2000; pp. 135159.

https://doi.org/10.1017/CBO9780511529320.009

[9] Carvalho L, Almeida IC, Felgueiras I, Leitão S, Boavida J, Santos PC et al. Best practices in early childhood intervention: a guide for professionals. Coimbra: ANIP; 2016.

[10] Decree-Law $n^{\circ} 281 / 2009$, de 6 de October. Creates the National Early Childhood Intervention System. Republic Diary - $1^{\text {a }}$ Série, 193:7298-7301.

[11] Dunst CJ. Parapatric speciation in the evolution of early intervention for infants and toddlers with disabilities and their families. Topics in early childhood special education. 2012; 31(4): 208-215. https://doi.org/10.1177/0271121411426904

[12] Guralnick MJ. International perspectives on early intervention: A search for common ground. Journal of early intervention. 2008; 30(90): 90-101.

https://doi.org/10.1177/1053815107313483

[13] Almeida IC. Family and community centered intervention: The gap between evidence and practices. Psychological Analysis. 2011; 1(29):5-25.

[14] Brown D. Training consultants: A call to action. Journal of Counseling \& Development. 1993; 72(2): 139-143. https://doi.org/10.1002/j.1556-6676.1993.tb00912.x 
[15] Buysse V, Wesley WP. Ethics and evidence in consultation. Topics in early childhood special education. 2006; 26: 131141. https://doi.org/10.1177/02711214060260030101

[16] Boavida T, Aguiar C, McWilliam RA (2018). Early intervention and early childhood contexts. In: Fuertes M, Nunes C, Lino $\mathrm{D}$, Almeida, T organizers. Theory, practices and research in early intervention. Lisbon: CIED/ Lisbon Higher School of Education; 2018. p. 7-23

[17] McWilliam RA. Routines-based early intervention: Strategies for supporting young children with disabilities. Baltimore, MD: Paul H. Brookes; 2010.

[18] Correia LM, Cabral MC. A new policy in education. In: Correia LM, organizers. Students with special educational needs in regular classes. Porto: Porto Publishing Company; 1999. p. $17-44$.

[19] Connor DJ, Ferri BA. The conflict within: resistance to inclusion and other paradoxes in special education. Disability and Society. 2007; 22(1): 63-77. https://doi.org/10.1080/09687590601056717

[20] Lopes L, Correia N, Aguiar C. Implementation of children's participation rights in the context of a kindergarten: educators' perceptions. Portuguese journal of education. 2016; 29(2):81-108.

[21] Charman T, Pellicano L, TEAcey L, TEAcey N, Forward K, Dackrell J. What is good practice in Autism Education. Autism Education Trust Report. Centre for Research in Autism and Education (CRAE). London: Institute of Education, University of London; 2011.

[22] Johnson CP, Myers SM. Management of Children with Autism Spectrum Disorders. Pediatrics. 2007;120(5): 11621182. https://doi.org/10.1542/peds.2007-2362

[23] Klin A. Autism and asperger's syndrome. An overview. Brazilian Journal of Psychiatry. 2006; 28(1):3-11.

[24] Kogan MD, Blumerg SJ, Schieve LA, Boyle CA, Perrin JM, Ghandour R, et al. Prevalence of parent-reported diagnosis of autism spectrum disorder among children in US, 2007. Pediatrics. 2009; 5(124): 1395-1403. https://doi.org/10.1542/peds.2009-1522

[25] Stevens M, Washington A, Rice C, Jenner W, Ottolino J, Clancy $\mathrm{K}$, et al. Prevalence of the autism spectrum disorders (ASDs) in multiple areas of the United States, 2000 and 2002. Atlanta, GA: Center for Disease Control and Prevention; 2007.

[26] Mottron L. Should we change targets and methods of early intervention in Autism in favor of a strengths-based education? European Child and Adolescent Psychiatry. 2017; 26: 815-825. https://doi.org/10.1007/s00787-017-0955-5

[27] Wing L, Gould J, Gillberg C. Autism spectrum disorders in the DSM-V: better or worse than the DSM-IV? Research in Developmental Disabilities. 2011; 32(2): 786-773. https://doi.org/10.1016/j.ridd.2010.11.003

[28] Correia LM. Inclusion and special needs education: a guide for educators and teachers $\left(2^{\mathrm{a}}\right.$ ed). Porto: Porto Publishing Company; 2008.

[29] Pereira APS, Serrano AM. Early intervention in Portugal: study of professionals' perceptions. Journal of Family Social Work. 2014; 17(3): 263-282. https://doi.org/10.1080/10522158.2013.865426

[30] Pego CM. The perceptions of families of children with special needs about the benefits of early intervention: a qualitative study with families from Braga (Masters' Dissertation). Braga: Minho's University - Institute of Child Studies; 2014.

[31] Carvalho JC. Study of ELI of the Braga and Bragança districts: a contribution to the evaluation of family-centered practices (Masters' Dissertation). Braga: Minho's University Institute of Child Studies; 2015
[32] Raimundo Al. Early Intervention and Autism Spectrum Disorder: needs and priorities of the families of children aged 3-6 years (Masters' Dissertation). Lisbon: University of Lisbon - Faculty of Human Motricity; 2015.

[33] Velez A. Typical practices and ideal collaborative consulting practices in early intervention: perception of professionals (Masters' Dissertation). Lisbon: ISPA - Higher Institute of Applied Psychology / University Institute of Psychological, Social and Life Sciences; 2016.

[34] Martins, TI. Discrepancy between typical and ideal practices in early childhood intervention: perception of professionals from local intervention teams in Portugal (Masters' Dissertation). Lisbon: ISCTE-IUL - School of Social and Human Sciences - Department of Social and Organizational Psychology; 2017.

[35] Gonçalves B. Typical and ideal practices in early intervention: the point of view of the professionals of the local intervention teams in Porto district (Masters' Dissertation). Porto: University of Porto - Faculty of Psychology and Educational Sciences; 2018.

[36] Gronita J. Contributions to the analysis of organizational models of early intervention in childhood in Portugal (PhD final thesis). Lisbon: Open University; 2014

[37] Duarte MD. Analysis of practices within the scope of local early intervention teams and special educationl: a comparative study (PhD final thesis). Lisbon: ISPA - Higher Institute of Applied Psychology / University Institute of Psychological, Social and Life Sciences; 2018.

[38] Bogdan R, Biklen S. Qualitative Research in Education: an introduction to data theory. Porto: Porto Publishing Company; 1994.

[39] Bardin L. Content analysis (revised and updated edition) Lisbon: 70 Editions; 2009.

[40] Pinto N, Morgado J. Attitudes of parents and teachers towards inclusion. Proceedings of the 12th Colloquium on Psychology and Education. ISPA. University Institute. Lisbon; 2012.

[41] Serrano A, Afonso J. ChildhoodeEducation in Inclusive contexts: an experience about Inclusion in five European countries. Diversities Magazine. 2010; 27:17-20.

[42] Hammond H, Ingalls L. Teachers' attitudes toward inclusion: survey results from elementary school teachers in three southwest rural school districts. Rural Special Education Quarterly. 2003; 22(2): 24-30. https://doi.org/10.1177/875687050302200204

[43] Camargo SPH, Bosa CA. Social Competence, Schoo Inclusion and Autism: Critical Literature Review. Psychology \& Society. 2009; 21(1):65-74. https://doi.org/10.1590/S0102-71822009000100008

[44] Kristen R, Brandt C, Connie K. General education teachers' relationships with included students with Autism. Journal of Autism and Developmental Disorders. 2003; 33: 123-130. https://doi.org/10.1023/A:1022979108096

[45] Bowker A, D'Angelo N, Hicks R, Wells K. Treatments for Autism: Parental Choices and Perceptions. Journal of Autism and Developmental Disorders. 2011; 41(10): 1373-82. https://doi.org/10.1007/s10803-010-1164-y

[46] Dunst CJ. Early intervention for infants and toddlers with developmental disabilities. In: Odom SL, Horner RH, Snell M Black J, organizadores. Handbook of developmental disabilities. New York, NY: Guilford Press; 2007. p. 161-180.

[47] Caldeira ZS, Seixas SR, Piscalho I. Routine-based intervention. UIIPS Magazine - Research Unit of the Polytechnic Institute of Santarém. 2017; 5(1):62-80.

[48] Dunst CJ, Bruder MB. Values outcomes of service coordination, early intervention, and natural environments. Council for Exceptional Children. 2002; 68(3): 361-375. https://doi.org/10.1177/001440290206800305 
[49] Mahoney G, MacDonald J. Autism and developmental delays in young children. International Journal of Early Childhood Special Education (INT-JECSE). 2009; 1(1): 95-101.

[50] Pimentel JS, Correia N, Marcelino S. The evaluation of practices as a contribution to promoting the quality of early intervention programs. Psychological Analysis. 2011; 1(29):47-65.

https://doi.org/10.14417/ap.38

Received on 03-02-2021

Accepted on 09-04-2021

Published on 01-06-2021

https://doi.org/10.6000/2292-2598.2021.09.03.7

(C) 2021 Caeiro and Franco; Licensee Lifescience Global.

This is an open access article licensed under the terms of the Creative Commons Attribution Non-Commercial License (http://creativecommons.org/licenses/by-nc/3.0/) which permits unrestricted, non-commercial use, distribution and reproduction in any medium, provided the work is properly cited. 